\title{
Psychological Profiling of Prisoners
}

\author{
Bhadkamkar M. ${ }^{1}$, Rejani T.G. ${ }^{2}$, Arvind A. ${ }^{3}$
}

\section{ABSTRACT}

Introduction: The relation between criminal behavior and different dimensions of personality features were studied extensively and available literature on offenders has described different personality traits observed in them. However very few literature is available on Indian population.

Aim: To find the prominent personality traits, attribution styles used and level of sensation seeking among prisoners.

Method: the study design used was cross-sectional design. 30 offenders from Sabarmati Central Jail were selected using purposive sampling.

Tools: To assess attribution style, personality traits and sensation seeking behavior, following tool were used. Attribution Style Questionnaire, Eysenck’s Personality Questionnaire, Brief Sensation Seeking Scale

Result:43\% prisoners scored high on neuroticism trait. 55\% prisoners showed extraversion and $60 \%$ females showed neuroticism as a predominant personality trait. $66.67 \%$ prisoners had internal locus of control. $76.67 \%$ prisoners had low level of sensation seeking.

Implication: this study will throw light upon the criminal behavior and personality of prisoners which will be beneficial for future therapy work.

Keywords: psychological profiling, attribution style, personality traits, sensation seeking

behavior, offender

All countries experience crime and violence which can lead to some of the following situations: countries with high proportions of young men who are killed before they become adults; societies with families who lose a parent or have members in prison, who are living in poverty and without access to support or legitimate sources of income; neighborhoods experiencing gang wars; women who are subjected to violence in their homes, or who are at risk of sexual assault in public spaces; and migrants and minority groups living in dilapidated and isolated areas or informal settlements subject to victimization. Thus we can conclude that crimes come with an enormous price.

\footnotetext{
1, 2, ${ }^{3}$ Institute of Behavioural Sciences, Gujarat Forensic Sciences University, Gujarat (C) 2015 I Bhad M, Rejani T, Arvind A; licensee IJIP. This is an Open Access Research distributed under the terms of the Creative Commons Attribution License (http://creativecommons.org/licenses/by/2.0), which permits unrestricted use, distribution, and reproduction in any Medium, provided the original work is properly cited.
} 


\section{Psychological Profiling of Prisoners}

Approximately 5\% of the population is responsible for a sizeable portion of the total amount of crime; thus, preventing high-risk individuals from developing into offenders can provide society with significant savings. To track high-risk individuals and tailor prevention programs, risk factors for criminal behavior must be identified. Knowledge about risk factors for criminal behavior can further expand the range of treatment possibilities and increase their effectiveness.

\section{EYSENCK'S THEORY OF CRIMINALITY}

The late Hans J. Eysenck, British psychologist, is most well-known for his theory on personality and crime. His theory proposed that' criminal behavior is there sult of an interaction between certain environmental conditions and features of the nervous system”. Followers of his theory believe that each individual offender has a unique neurophysiological makeup that when mixed with a certain environment, therefore, can't help but result to criminality (Bartol et al., 2005). It is important to note that Eysenck was not suggesting that criminals are born, rather that the combination of environment, neurobiological, and personality factors give rise to different types of crimes, and those different personalities were more susceptible to specific criminal activity. It is not criminality that is innate; it is certain peculiarities of the central and autonomic nervous system that react with the environment, with upbringing, and many other environmental factors to increase the probability that a given person would act in a certain antisocial manner (Eysenck\& Gudjonsson,1989). Eysenck shows three main factors for temperament, being extraversion, neuroticism, and psychoticism. In his theory of criminality, Eysenck proposed that personality is linked to criminality through socialization process. In the socialization process, children who act in immature ways for immediate gratification are punished. As a consequence of the punishment they experience anxiety and that anxiety is associated with antisocial behaviour. As a result of this conditioning, a mere thought about behaving antisocially produces anxiety in an individual and thus, the person avoids indulging into such an act.

According to the theory, people who have high level of extraversion and neuroticism trait have nervous system that makes them difficult to condition. Thus, the antisocial impulse in them does not produce anxiety and they are prone to act antisocially if the situation is demanding such an act. A study conducted to evaluate Eysenck's theory showing relationship between Eysenck's personality traits and criminal convictions showed that offenders showed higher Psychoticism and Neuroticism scores but not necessarily higher Extraversion scores (Hollin, 1989).

\section{Sensation Seeking}

According to the 'arousal-seeking theory, some people's brains function differently in response to environment stimuli due to variety of genetic and environmental reasons and they try to reach a level of arousal from the environment. If there is not adequate stimulation it results in boredom and eventually anxiety. And this anxiety leads to sensation seeking. This theory also says that sensation seekers are biologically and environmentally prone to engage in deviant activities and to take illicit drugs (Lee, 1996). According to this theory, obtaining thrills and a demonstration of competence are the main crime motivators, usually with little to no economic gain (Katz, 1988).Sensation seeking, as defined by Zuckerman, is a personality trait having a biological basis 


\section{Psychological Profiling of Prisoners}

that expresses as a need for physiological arousal, novel experience, and a willingness to take social, physical, and financial risks to obtain such arousal (Zuckerman, 1994). Sensation seeking is associated with a variety of illegal and/or risky behaviors such as the use of illicit drugs (Newcomb and McGee, 1991; Palmgreen et al., 2001; Stephenson et al., 2003; Zuckerman M., 1993), sexual risk-taking (Donohew et al., 2000; Hoyle et al., 2000), reckless driving (Heino et al., 1996), smoking (Zuckerman et al., 1990), and alcohol use (Stacy et al., 1993).

Zuckerman predicted that many or all of the kinds of risky activities would be related to impulsive sensation-seeking. He also assessed smoking, drinking, drug use, sex, driving and gambling on separate risk-taking scales related to each particular kind of risky behaviour. He could establish that the six arenas of risk were interrelated, pointing to a concept of generalized risk-taking.

Gender differences in sensation seeking are apparent. According to a study, male subjects were more likely than female subjects to exhibit all different types of delinquent and deviant behavior (Newcomb \& McGee, 1991).

\section{LOCUS OF CONTROL}

In personality psychology, locus of control refers to the extent to which individuals believe they can control events affecting them. Understanding of the concept was developed by Julian B. Rotter in 1954. A person's "locus" (Latin for "place" or "location") is conceptualized as either internal (the person believes they can control their life) or external (meaning they believe their decisions and life are controlled by environmental factors which they cannot influence, or by chance or fate).

There is little guidance in the literature concerning the relationship between criminality and locus of control. However research shows that Offenders who had been physically abused as children were more externally controlled. External locus of control was also found to be related to higher risk of reconviction for future sexual offending and less adjustment among inmates.

It was also found that active offenders and desisting ex-offenders differ in terms of explanatory style; i.e., offenders tend to interpret negative events in their lives as being the product of internal, stable, and global forces (e.g., "That's just the type of person I am, Bad to the bone, Born to lose, etc.) whereas they tend to view positive events in their lives as being the product of external, unstable, and specific causes (i.e., "lucky breaks"). These dimensions of offender cognitions may be useful in understanding the psychological aspects of desistance from crime. It also suggests an interesting, possible relationship between explanatory style and criminal desistance. First, negative-internal attributions are associated with persisting in criminal behavior. Someone might be less able to desist to the extent that negative events are seen as originating from internal sources ("This is just the way I am") — especially when these are stable ("I’ve always been this way”) and global ("I fail at everything I do, no matter where I go”) 


\section{Psychological Profiling of Prisoners}

characteristics. One might speculate, therefore, that the more individuals are able to attribute positive life events to broad,long-lasting personal qualities (e.g., "Because I am a worthy individual"), the greater the odds may be that they will be able to stay crime free (S. Maruna, 2004).

The research that follows will investigate the relation between criminal behavior and different dimensions of personality features. The study aims to find the psychological profiling of prisoners which includes personality traits, locus of control used and levels of sensation seeking.

\section{METHODOLOGY}

Objective: The objectives of this study were as follows

- $\quad$ To find out prominent personality traits among prisoners.

- To find our prominent locus of control among prisoners.

- $\quad$ To find out the level of sensation seeking among prisoners

Research design: Cross-Sectional research design was used in this study.

Sample: Through purposive sampling method, total of 30 inmates were included in this study. This sample consisted of 20 male prisoners and 10 female prisoners. Mean age of the participants was 41 years. The participants were taken from Sabarmati Central Jail, Ahmedabad. Participants who could read and write were included in this study and those who were illiterates were excluded from the study.

Measures: Each participant was given 3 scales to measure their personality traits, locus of control and sensation seeking trait.

Personality trait was measured using Eyesenck Personality Questionnaire (EPQ). It consisted of total 90 items. This instrument is designed to measure three major dimensions of personality, namely psychoticism, neuroticism, and extraversion. It also gives measure of lie scale. Subscales of the EPQ-R have displayed acceptable levels of internal consistency reliability for example, reliability estimates ranging from .89 to .91 for Extraversion, from .84 to .86 for Neuroticism, and from .67 to .68 for Psychoticism.

Locus of control was measured using Rotter's Locus of Control Scale. It is a 29 items forced choice questionnaire. This tool identifies whether an individual has an internal or external locus of control. Test-retest reliability of the scale was .61.

Sensation seeking was measured usingshortened version of Zuckerman's scale. It is a 13 items forced choice questionnaire. This scale measures whether an individual has high or low level of sensation seeking.

Statistical analysis: Results were analyzed using descriptive statistics. Percentages were calculated. 


\section{Psychological Profiling of Prisoners}

Procedure: Participants who were willing to participate in the study were first given consent from and a demographic data sheet. They, then were given the all the questionnaires to fill.

\begin{tabular}{|c|c|c|c|}
\hline & Males & Females & Both \\
\hline Psychoticism & $10 \%$ & $40 \%$ & $20 \%$ \\
\hline Neuroticism & $35 \%$ & $60 \%$ & $44 \%$ \\
\hline Extraversion & $55 \%$ & $0 \%$ & $36 \%$ \\
\hline Lie Score & $100 \%$ & $90 \%$ & $96.67 \%$ \\
\hline
\end{tabular}

Table 1: Percentage of prisoners exhibiting 3 personality traits

$44 \%$ of all the prisoners showed neuroticism as the predominant personality trait. It was followed by extraversion (36\%) and psychoticism (20\%).Among males, 55\% prisoners scored high on extraversion trait, followed by neuroticism (35\% and psychoticism (10\%).60\% females also showed neuroticism as the predominant personality trait. Remaining $40 \%$ of the females scored high on psychoticism. No female obtained high score on extraversion.

When scored lie scale it was found that all except one prisoner, showed elevated scores on lie scale.

\begin{tabular}{|c|l|l|l|}
\hline & Males & Females & Both \\
\hline Internal LOC & $55 \%$ & $60 \%$ & $66.67 \%$ \\
\hline External LOC & $45 \%$ & $40 \%$ & $33.33 \%$ \\
\hline
\end{tabular}

Table 2: Percentage of prisoners exhibiting internal and external locus of control

$66.67 \%$ of all the prisoners showed internal locus of control. The same patternwas also observed in males and females separately. $55 \%$ males and $40 \%$ females had internal locus of control.

\begin{tabular}{|c|l|l|l|}
\hline & Males & Females & Both \\
\hline $\begin{array}{c}\text { High } \\
\text { Sensation Seeking }\end{array}$ & $30 \%$ & $10 \%$ & $23.33 \%$ \\
\hline $\begin{array}{c}\text { Low Sensation } \\
\text { Seeking }\end{array}$ & $70 \%$ & $90 \%$ & $76.67 \%$ \\
\hline
\end{tabular}

Table 3: Percentage of prisoners exhibiting high and low sensation seeking trait

When reviewed sensation seeking trait, it was found that $76.67 \%$ of all the prisoners showed low level of sensation seeking. When scored separately, it was observed that $70 \%$ males and $90 \%$ females scored low on sensation seeking trait. 


\section{DISCUSSION}

On personality assessment neuroticism was found to be the predominant trait among all the prisoners. Male prisoners showed extraversion as the predominant personality trait. People who score high on extraversion usually tend to be sociable, active, impulsive, uninhibited and sensation seekers. They prefer excitement and often act on spur of the moments. A person can be impulsive and sensation seeker without being a prisoner however these traits have been identified as a risk factor for being a criminal. Females also showed neuroticism as predominant personality traits. People with elevated scores on neuroticism generally are anxious, depressed and react strongly to aversive stimuli.

Previous researches on personality traits have shown that prisoners tend to score high on all the three dimensions that is neuroticism, psychoticism and extraversion compared to normal population. However current study has examined the predominant personality trait among the prisoners. According to previous studies, women obtain higher means than men on neuroticism and men obtained higher means than women on extraversion (Lynn \& Martin, 1997). As suggested by previous research, females are more neurotic in nature and they are more prone to mood and anxiety disorders. The current study has also shown the similar personality pattern among female prisoners.

Apart from the three dimensions, all except one, showed elevated scores on lie scale. This shows the tendency to give socially desirable answers. As most of the prisoners were not habitual criminals, they might have given socially desirable answers to avoid negative attention and present themselves in more favorable light. However due to high lie score, the results need to be treated in a cautious way.

Majority of the prisoners (66.67\%), both males (55\%) and females (60\%), showed internal locus of control. Previous research has shown that active offenders were observed to interpret negative events in their lives as being the product of internal, stable, and global forces and good events were the product of external, unstable and specific causes (Maruna, 2004). Thus current results can be explained in the light of this previous study. However, more studies considering all the aspects of attribution style can give a more detailed picture.

When reviewed the sensation seeking trait, it was found that most of the prisoners showed low level of sensation seeking. Previous researches have consistently shown a relationship between high levels of sensation seeking with risky behaviours. A study has also found that measures of impulsivity and sensation seeking in male preschoolers are the best available predictors of delinquency at age 13. In the current study most of the prisoners were of middle age (35-55 years) which could have resulted in low levels of sensation seeking. Also, all the males and many of the females were in jail for more than 5 years. Thus it is possible that years spent in jail might have affected their sensation seeking behaviour. Apart from these, another aspect is the nature of the crime. Most of the criminals assessed had committed murder. Murder mostly is a situational 


\section{Psychological Profiling of Prisoners}

crime and it may not induce high level of sensation seeking. A similar study on different kinds of crimes could have given different results. A longitudinal study found that $33 \%$ of the serious delinquents were low sensation seekers with dull-normal intelligence, suggesting that low sensation seekers can also be involved in delinquency too (Gatzke-Kopp et.al., 2002).It is also possible that instead of involving into various sensation seeking activities, such as skydive, bungee jump, race cars, and adventure safaris, their kicks might just be criminal in nature. Also the nature of sensation seeking may differ from one culture to another. In India the nature and level of sensation seeking may not match with that in other countries due to social and cultural differences.

\section{CONCLUSION}

Among the prisoners, neuroticism was found to be the most predominant trait; however males showed extraversion as the predominant personality trait. Majority of the inmates showed internal locus of control and showed low sensation seeking trait.

\section{FUTURE DIRECTION}

Future studies in this area can focus on larger sample size and in depth exploration of various factors. A comparative study with non-offenders can prove comprehensive. Among the prisoners, neuroticism was found to be the most predominant trait; however males showed extraversion as the predominant personality trait. Majority of the inmates showed internal locus of control and showed low sensation seeking trait.

\section{IMPLICATION}

Different psychological factors such as personality, locus of control and sensation seeking have an effect on a person's behaviour. Thus findings of this study can help to make a prevention plan as well as rehabilitation module for prisoners.

\section{BIBLIOGRAPHY}

Bartol, Anne M. and Bartol, Curt A. (2005). Criminal behavior: A psychosocial approach. Upper Saddle River, New Jersey: Pearson Prentice Hall

Donohew, L., Zimmerman, R., Cupp, P. S., Novak, S., Colon, S., \&Abell, R. (2000). Sensation seeking, impulsive decision-making and risky sex: implications for risk-taking and design of interventions. Personality and Individual Differences, 28, 1079-1091.

Eysenck, H., Gudjonsson, G. (1989). The causes and curses of criminality .New York: Plenum Press.

Fisher, D., Beech, A., Browne K. (1998). Locus of control and its relationship to treatment change and abuse history in child sexual abusers, Legal and criminological psychology, 3,(1), 1-12. 


\section{Psychological Profiling of Prisoners}

Gatzke-Kopp, L., Raine, A., Loeber, R., Stouthamer-Loeber, M., \&Steinhauer, S. (2002). Serious delinquent behavior, sensation seeking, and electrodermal arousal. Journal of Abnormal Child Psychology, 30, 477-486.

Heino, A., van der Molen, H. H., \& Wilde, G. J. S. (1996). Differences in risk experience between sensation avoiders and sensation seekers. Personality and Individual Differences, 20, 71-79.

Hollin, C. (1989). Psychology and crime: An introduction to criminological psychology. New York: Routledge

Hoyle, R. H., Fejfar, M. C., \& Miller, J. D. (2000). Personality and sexual risk-taking: a quantitative review. Journal of Personality, 68, 1203-1231.

Katz, J. (1988). Seduction of Crime: Moral and Sensual Attractions of Doing Evil. New york: Basic Books.

Lee, E. (1996). Arousal Theory and the Religiosity-Criminality Relationship. Contemporary Criminology Theory, 65-84.

Lynn, R., \& Martin, T. (1997). Gender Differences in Extraversion, Neuroticism, and Psychoticism in 37 Nations. The Journal of Social Psychology, 137, 369-373.

Maruna, S. and S. Farrall (2004) 'Desistance from Crime: A Theoretical Reformulation', 43:171-194 .

Newcomb, M. D., \& McGee, L. (1991). Influence of sensation seeking on general deviance and specific problem behaviors from adolescence to young adulthood. Journal of Personality and Social Psychology, 61, 614-628.

Page, G., \&Scalora, M. (2004). The utility of locus of control for assessing juvenile amenability to treatment. Aggression and Violent Behavior, 5, 523-534.

Palmgreen, P., Donohew, L., Lorch, E. P., Hoyle, R. H., \& Stephenson, M. T. (2001). Television campaigns and adolescent marijuana use: tests of sensation seeking targeting. American Journal of Public Health, 91, 292-295.

Stacy, A. W., Newcomb, M. D., \&Bentler, P. M. (1993). Cognitive motivations and sensation seeking as long-term predictors of drinking problems. Journal of Social and Clinical Psychology, 12, 1-24.

Stephenson, M., Hoyle R., Palmgreen P., Slater, M. (2003). Brief measures of sensation seeking for screening and large-scale surveys. Drug and Alcohol Dependence, 72, 279-286.

Tremblay, R., R. Pihl, Viaro, F., \&Dobkin, P. (1994). Predicting early onset of male antisocial behavior from preschool behavior. Archives of General Psychiatry, 51, 732-739.

Zuckerman, M. (1993). P-impulsive sensation seeking and it's behavioral, psychophysiological, and biochemical correlates. Neuropsychobiology, 28, 30-36.

Zuckerman, M. Hello (1994). Behavioral Expressions and Biosocial Bases of Sensation Seeking. 